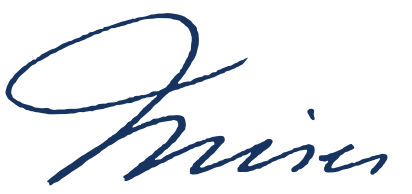

\title{
Direitos de propriedade privada e a resolução da externalidade pelo processo de mercado
}

\author{
João Roberto Lo Turco Martinez ${ }^{\mathrm{I}}$ (1) 0000-0002-0890-5977 \\ Universidade Federal do Triângulo Mineiro - Uberaba - Minas Gerais - Brasil
}

Resumo: Este trabalho tem como objetivo estudar o processo de mercado e suas possíveis falhas comumente citadas nos textos e estudos de economia mainstream que, mesmo quando argumentam contra a interferência estatal na economia, justificam exceções com bases nestas supostas falhas. Então, escolhendo uma das falhas mais comumente citadas - as externalidades - este trabalho analisa como este problema seria resolvido (e até mesmo não criado) pela definição precisa de direito de propriedade privada e pelo livre mercado por meio de revisão teórica de autores da economia mainstream e da Escola Austríaca sobre mercados, falhas de mercados, externalidade entre outros. Assim, pode-se evoluir o raciocínio da economia mainstream corrigindo-o por meio da praxeologia da Escola Austríaca e mostrar que uma solução de mercado por meio de direitos precisos de propriedade privada para o problema das externalidades é mais eficiente tanto em evitá-la como em solucionála caso ocorra.

Palavras-chave: Mercado, Externalidade, Propriedade, Falhas de Mercado, Direitos.

\footnotetext{
${ }^{\text {I }}$ Doutor em Administração de Empresas pela Fundação Getúlio Vargas (Escola de Administração de Empresas de São Paulo-2012) e Mestre em Administração, Dinâmica e Gestão de cadeias produtivas pela Universidade Federal de Lavras (2008). Possui graduação em Administração, graduação em Direito, graduação em Economia e graduação em Contabilidade. Também obteve especialização em Ciência Política, Economia do Setor Público, Contabilidade Forense e Fraudes Contábeis, Filosofia, Neurociências e Processos Psicológicos e em Engenharia de Produção. Atualmente, é professor da Universidade Federal do Triângulo Mineiro. E-mail: prof.joaoroberto01@gmail.com.
} 


\title{
Private property rights and the resolution of externality through the market process
}

\begin{abstract}
This paper aims to carry out a narrative review of the market and its possible failures commonly cited in mainstream economics texts and studies that, even when they argue against state interference in the economy, justify exceptions based on market failures. So, choosing one of the most commonly cited market failures - the externalities - this paper analyzes how this problem would be solved (and even not created) by the precise definition of private property rights and by the free market through theoretical review by mainstream economics authors and the Austrian School on markets, market failures, externalities, among others. Thus, making the rationale of mainstream economics evolve by correcting it through Austrian School praxeology and show that a market solution through precise private property rights to the problem of externalities is more efficient both in avoiding it and in solving it if it occurs.
\end{abstract}

Keywords: Market, Externality, Property, Market Failures, Rights.

\section{Derechos de propiedad privada y resolución de externalidad por parte del proceso de mercado}

Resumen: Este artículo tiene como objetivo hacer una revisión narrativa sobre el mercado y sus posibles fallas comúnmente citadas en los textos y estudios de economía dominante que, incluso cuando argumentan en contra de la interferencia del Estado en la economía, justifican excepciones sobre la base de fallas. Por lo tanto, destaque una de las fallas más comúnmente citadas, como las externalidades, este artículo analiza cómo este problema se resolvería (e incluso no se crearía) mediante la definición precisa de los derechos de propiedad privada y por el libre mercado a través de una revisión teórica por parte de los principales autores económicos y la Escuela Austriaca sobre mercados, fallas de mercado, externalidades, entre otros. Por lo tanto, se puede desarrollar el razonamiento económico convencional corrigiéndolo a través de la praxeología de la escuela austriaca y mostrar que una solución de mercado a través de derechos de propiedad privada precisos al problema de las externalidades es más eficiente tanto para evitarlo como para resolverlo si ocurre.

Palabras clave: Mercado, Externalidad, Propiedad, Fallos del mercado, Derechos. 


\section{Introdução}

Para Mises (2010, p. 316), o mercado é um processo que faz o ajustamento das ações individuais dos vários membros da sociedade aos requisitos da cooperação mútua, no qual os preços informam aos produtores o que produzir, como produzir e em que quantidade produzir. Assim, qualquer interferência governamental na livre concorrência, seria prejudicial (GARCIA et al., 2019, p. 21), pois mercados competitivos alocam de modo eficiente o conjunto de recursos disponíveis da sociedade (SMITH, 2018, p. 22).

A economia mainstream tenta justificar a intervenção governamental nos mercados baseado no argumento de que, no mundo real, se observariam desvios em relação ao modelo ideal preconizado por Adam Smith devido as chamadas imperfeições de mercado: externalidades, informação imperfeita e poder de monopólio e oligopólio (GARCIA et al., 2019, p. 21). Para resolver este problema, a maioria dos economistas supunha que a ação governamental poderia e deveria ser usada para corrigir problemas oriundos das falhas de mercado (BUTLER, 2015, p. 30).

Porém, a visão de que a intervenção governamental generalizada era necessária para aumentar o bem-estar social por meio de correção dos casos de falha de mercado começaram a ser questionados pelo real problema da falha de governo, e que problemas como monopólios, externalidades e informação limitada ou desigual eram muito mais evidentes no governo do que nos mercados e, por causa da natureza de "o vencedor leva tudo" nas decisões públicas, a oportunidades de se escapar das falhas de governo eram muito menores (BUTLER, 2015, p. 30). Assim, as falhas governamentais e os problemas com a intervenção governamental podem ser ainda mais nocivos do que aqueles que se pretendem corrigir no mercado (BUTLER, 2015, p. 40).

Ao invés de se evitar as intervenções governamentais e procurar uma solução por meio do mercado, muitas doutrinas não reconhecem a tendência empresarial para detectar e corrigir desajustamentos e, como as interferências governamentais acabam por gerar dolorosos reajustamentos para corrigir os efeitos da intervenção, surge um espaço ideal para justificar novas interferências e para os argumentos populares de insuficiências econômicas do mercado (SOTO, 2012, p. 390).

A visão da Escola Austríaca de Economia critica a ausência de conhecimento por parte do regulador, de forma que sua ação é tomada utilizando apenas um pequeno referencial amostral, agindo de forma equivocada para determinar correções, via regulação, de imperfeições no mercado (MAZZONI, 2019). Isso porque, as escolas mainstream, que recomendam ações para um regulador, tem uma errônea compreensão do que são mercados, da impossibilidade de situação de equilíbrio de mercado, do não entendimento de que os mercados serem processos dinâmicos que tendem ou não ao equilíbrio (nunca o alcançando no mundo real), de que o tempo dinâmico influi nas decisões tomadas no mercado e de que o conhecimento é parcial e disperso (IORIO, 2013).

Porém, mesmo dentro da economia mainstream, alguns poucos autores propõem soluções para as supostas falhas de mercado por meio do próprio mercado e sem a coerção e ineficiência 
governamental. Coase apud Mochón (2008, p. 124) propõe, para o caso das externalidades, uma ação alternativa à ação governamental mediante a fixação de direitos de propriedade perfeitamente definidos. Neste caso, as partes podem resolver por si mesmas os problemas das externalidades (se o mercado não aloca os recursos de forma eficiente, é porque o direito de propriedade não está perfeitamente estabelecido), pois se todos os recursos disponíveis em quantidade limitada tiverem um proprietário é possível impedir que terceiros utilizem o recurso e permitir que estes recursos possam ser transferidos.

Assim, o objetivo deste trabalho é fazer um estudo sobre o processo de mercado e suas possíveis falhas, por meio de referenciais das escolas econômicas mainstream e de autores e princípios da denominada Escola Austríaca (alguns autores da economia mainstream acabam, por vezes, em seus argumentos, defendendo princípios cuja base praxeológica estão na Escola Austríaca), analisando especificamente as externalidades (em termos das definições da economia mainstream) e como ela seria resolvida (e até mesmo não criadas) pela definição precisa de direito de propriedade privada e do livre mercado, resolvendo um problema da economia mainstream utilizado para justificar a existência e intervenção governamental, com a base praxeológica da Escola Austríaca. Para isso, foi feito uma revisão de literatura narrativa ou tradicional, que é um método de mapear conhecimentos mais amplos por meio de critérios abertos de revisão de estudos, sendo a seleção dos estudos analisados de concordo com a intenção argumentativa do pesquisador, sujeitas ao viés de seleção de acordo com sua percepção subjetiva (CORDEIRO et al., 2007, p. 429).

\section{O Processo de Mercado}

A economia de mercado é o sistema social baseado na divisão do trabalho e na propriedade privada dos meios de produção, por meio do qual, ao agir, todos servem seus concidadãos e são servidos por eles, sendo cada um ao mesmo tempo um meio e um fim. Isto pelo fato de ser por acordo, trocas ou compras que obtemos uns dos outros a maior parte daquelas necessidades múltiplas que esperamos (MISES, 2010, p. 315). As diferenças de habilidades são de uso particular, porém, as produções destas habilidades podem ser usufruídas por toda a sociedade por meio de uma ação comum dado pelo processo de troca. Por ser o poder da troca capaz de gerar a divisão do trabalho, da mesma forma a extensão dessa divisão deve sempre ser limitada pela extensão dessa força ou em outras palavras pelo tamanho do mercado (SMITH, 2018, p. 25).

Assim, o mercado é um processo (não é uma coisa, lugar ou entidade coletiva) no qual as pessoas cooperam por meio da divisão do trabalho, que surge do conjunto de relação de troca estabelecido pela interação daqueles que estão desejosos de vender com aqueles estão desejosos de comprar e que realizam essas trocas por um meio indireto, o chamado dinheiro ou moeda, pelo qual é possível determinar preços para avaliar e calcular decisões (MISES, 2010, p. 315).

A situação do mercado depende de julgamentos de valor dos indivíduos e suas ações baseadas nestes julgamentos e que resultam, em um determinado instante, em uma determinada 
estrutura de preço. Então, o processo de mercado é o ajustamento das ações individuais dos vários membros da sociedade aos requisitos da cooperação mútua, no qual os preços de mercado informam aos produtores o que produzir, como produzir e em que quantidade produzir (MISES, 2010, p. 316).

\section{Falhas de Mercado}

Segundo alguns teóricos da economia mainstream, o mercado (sem falhas) evolui em direção ao estado de equilíbrio geral que é ao mesmo tempo um ótimo de Pareto, ou seja, uma mudança na localização dos recursos não poderá melhorar a posição de um ou mais participantes sem que o outro fique pior (MACKAAY et al., 2015, p. 122). Porém, para estes autores, a existência deste mercado competitivo tem como premissas: a concorrência em todos os mercados, a informação completa de todos os participantes a respeito das posições disponíveis e, por fim, a apropriação de todos os bens e serviços negociados no mercado que permitirá a imputação de todo o custo de produção ao produtor e não a terceiros (MACKAAY et al., 2015, p. 122), em outras palavras, esses mercados competitivos esgotam os ganhos de troca entre os agentes, desde que não ocorram imperfeições ou falhas de mercado: monopólios e oligopólios, assimetrias de informação e externalidades (GARCIA et al., 2019, p. 21).

O poder de mercado caracteriza-se quando um produtor ou grupo de produtores aumenta os preços ou reduz a quantidade produzida ou diminui a qualidade a variedade de produtos ou serviços com a finalidade de aumentar lucros. As falhas de informação ocorrem quando os agentes econômicos não tem informação completa a respeito de determinado bem ou serviço e, por isso, eles não tomaram decisões corretas (GARCIA et al., 2019, p. 21). Já as externalidades ocorrem quando a produção ou o consumo de um bem afeta diretamente consumidores ou empresas que não participam de sua compra ou sua venda e quando esses efeitos não se refletem totalmente nos preços de mercado (MOCHÓN, 2008, p. 121). Este trabalho, concentrase na análise das externalidades e sua solução por mecanismos de mercado.

O primeiro teorema da teoria econômica do bem-estar mostra que um mercado livre proporciona um resultado eficiente na falta de externalidades (VARIAN, 2012, p. 680). As externalidades acontecem quando a produção ou consumo de um bem acarreta efeitos, positivos ou negativos, sobre outros indivíduos ou empresas, que não se refletem nos preços de mercado (GARCIA et al., 2019, p. 21), ou seja, quando a produção ou o consumo de um bem afeta diretamente consumidores ou empresas que não participam de sua compra ou sua venda e quando esses efeitos não se refletem totalmente nos preços de mercado, o que impedem a eficiência econômica (MOCHÓN, 2008, p. 121) do ponto de vista social, na medida em que os agentes não incorporam ou internalizam todos os custos ou benefícios possíveis para tomada de decisão, sendo esta externalidade ou negativa (a exemplo da poluição) ou positiva - a exemplo da educação (VASCONCELLOS et al., 2011, p. 281). As externalidades negativas impõem uma parcela de custo de uma atividade a terceiros (MACKAAY et al., 2015; p. 123) e fazem o mercado produzir uma quantidade maior que a socialmente desejável (MOCHÓN, 2008 , p. 121) e, as positivas lidam com uma vantagem não compensada em face de quem produz 
e os bens produzidos (MACKAAY et al., 2015, p. 123) e faz com que o mercado produza uma quantidade menor do que a socialmente desejável (MOCHÓN, 2008, p. 123).

Muitos exemplos de externalidades ocorrem do uso de recursos comuns ou do fornecimento de bens públicos. Neste ponto, a tragédia do uso comum refere-se à tendência da propriedade comum de ser utilizada de forma predatória e ineficiente e é uma forma predominante de externalidade (VARIAN, 2012, p. 702).

Apesar da maioria das falhas resultarem de defeitos extramercado de natureza institucional e, se ocorrerem de fato, elas serem amplificadas como consequência da intervenção governamental, um dos argumentos mais utilizados para tentar justificar o intervencionismo do estado no processo de mercado é alegação de que as "imperfeições e falhas" do mercado exigem correções por parte do poder público. Esse tipo de argumento resulta de uma errônea compreensão do que são mercados, da impossibilidade de situação de equilíbrio de mercado, do não entendimento de que os mercados serem processos dinâmicos que tendem ou não ao equilíbrio (nunca o alcançando no mundo real), de que o tempo dinâmico influi nas decisões tomadas no mercado e de que o conhecimento é parcial e disperso (IORIO, 2013).

Cordato (1980; 2004; 2007) explica que a economia neoclássica se baseia no perfeito equilíbrio geral competitivo e no Ótimo de Pareto e que, discordando destes princípios, os economistas austríacos argumentam que o perfeito equilíbrio geral competitivo é um guia conceitualmente falho, irrelevante e não operacional para uma política pública no mundo real, visto que as atividade do mercado deve ser analisada como um processo dinâmico, os conceitos de valor e utilidade são subjetivos e não podem ser observados e mensurados, o conhecimento do fenômeno do mercadológico por um agente participante ou para o fazedor de política são sempre imperfeitos, dado que a informação está dispersa nos agentes de mercado e os sinais estão continuamente sendo enviados pelo sistema de preço, resultando no fato de que nenhuma autoridade central pode ter todas as informações necessárias para determinar a solução de equilíbrio para qualquer ponto no tempo e todas os pontos futuros. Assim, todos os outros custos e benefícios das externalidades são experimentados subjetivamente e não podem ser "somadas" em um "custo-benefício social".

Para melhor definir o quadro institucional ideal para a economia austríaca, Cordato (1980; 2004; 2007) adota conceito de eficiência catalática para estabelecer os critérios de melhor ou pior para guiar como um sistema pode ser melhorado, sendo esta eficiência a expressão correta da eficiência social. Assim, a catalaxia é a ordem social gerada pelas atividades de mercado de indivíduos e organizações, cada um buscando seus próprios objetivos e as ineficiências cataláticas são resultado de ineficiências econômicas que são impostas sobre relações interpessoais particularmente no processo de troca e no sistema de preço (CORDATO, 1980; 2004; 2007), corroborando com o conceito de eficiência social de Kirzner (1963, p. 36) que defende ser a eficiência de um sistema social dependente do grau de coordenação com o qual as atividades separadas dos participantes e seus objetivos são coordenadas, ou seja, a eficiência com o qual ele permite seus membros individuais atingirem seus vários objetivos.

Disso resulta que o único tipo de externalidade relevante é aquela que surge por causa dos direitos de propriedade que não são claramente definidos ou que não são estritamente forçados. 
Isso porque, as ineficiências ditas de mercado são causadas pelo conhecimento imperfeito e são resolvidas pelos próprios agentes por meio de tentativa e erro, porém, as ineficiências verdadeiramente problemáticas e não resolvidas são as deficiências institucionais que são geradas pelo desvio do quadro institucional ideal de mercado (CORDATO, 1980; 2004; 2007).

O conceito austríaco de eficiência difere do neoclássico por ver a eficiência a partir de ações individuais em que os próprios indivíduos interessados são os melhores juízes para julgar o que são falhas e o que não são (IORIO, 2013). Assim, pode-se verificar que os pressupostos de eficiência de mercado são diferentes entre as escolas mainstream e a Escola Austríaca e, assim, as supostas falhas de mercado de uma, podem não ser falhas para a outra. Porém, neste trabalho, tentar-se-á mostrar que, mesmo para uma visão mainstream de eficiência de mercado, a Escola Austríaca oferece explicações mais racionais e soluções mais eficientes.

\subsection{Bens Coletivos (Recursos Comuns e Bens Públicos) e Bens Privados: a Rivalidade e a Exclusão}

Para a economia mainstream, bens privados são bens excludentes e na maioria das vezes rivais. Excludente porque é possível impedir os que não pagam pelo bem de os consumir e rival porque, quando uma pessoa consome, a outra não poderá consumir. Assim, bens que não podem ser excluídos do consumo (não excludentes) não despertam interesse do mercado (MOCHÓN, 2008, p. 126), já os bens exclusivos, sejam rivais ou não, podem ser providos privadamente (VASCONCELLOS et al., 2011, p. 283). Aqueles bens que não permitem que alguém seja excluído do seu uso são chamados de bens coletivos e resultam em incentivos para o abuso no seu uso (MACKAAY et al., 2015, p. 123).

Uma das subcategorias de bens coletivos são os recursos comuns, ou seja, aqueles cujos serviços são utilizados tanto na produção como no consumo, não sendo propriedade de nenhum indivíduo particular, tais como os peixes no mar aberto. Dos recursos comuns surge a externalidade negativa denominada tragédia dos bens comuns que mostra que os recursos comuns são utilizados em uma intensidade maior que a desejável sobre o ponto de vista da sociedade (MOCHÓN, 2008, p. 129), ou seja, esses bens comuns tendem a ter um consumo predatório e por isso ineficiente socialmente (VASCONCELLOS et al., 2011, p. 284).

Outra subcategoria de bens coletivos são os bens públicos, que são mercadorias ou serviços dos quais o uso não se pode excluir ninguém. Neste contexto aparece a figura do consumidor carona, isto é, aquele que goza os benefícios de um bem, mas evita pagar por isso (MOCHÓN, 2008, p. 128).

Vasconcellos et al. (2014, p. 284) acrescenta que os bens públicos tem um baixo grau de exclusividade e seu provimento gera benefício a todos ou a um número muito grande de agentes, mas não é fácil identificar os benefícios marginais de cada um (segurança em uma rua do bairro, por exemplo) e faz com que os agentes tenham um incentivo para não cooperarem, gerando o famoso "carona" que se beneficia do bem-estar gerado pelos bens públicos tendo cotizado ou não para o seu desenvolvimento. 


\subsection{As estratégias de enfrentamento das supostas falhas de mercado}

Na economia mainstream, a sociedade pode resolver os problemas de externalidade adotando algumas estratégias, tais como as descritas por Vasconcellos et al. (2011, p. 282-283): fusão de processos produtivos, direitos de propriedade, regulação estatal e o imposto de Pigou. A mesma conclusão chega Varian (2012, p. 701) quando diz que a solução para produção de externalidade inclui a utilização de impostos de Pigou, estabelecimento de um mercado para externalidade, a simples permissão para que as empresas possam se fundir e outros modos de transferência de direitos de propriedade. A suposição de que a ação governamental poderia e deveria ser usada para corrigir problemas oriundos das falhas de mercado começou a ser contestada, pois resultados demonstram que falhas de mercado não significam necessariamente que a ação governamental seja melhor, pois também existem falhas governamentais (BUTLER, 2015, p. 40) e que problemas como monopólios, externalidades e informação limitada ou desigual eram muito mais evidentes no governo do que nos mercados e, por causa da natureza de "o vencedor leva tudo" nas decisões públicas, a oportunidade de se escapar era muito menor (BUTLER, 2015, p. 30).

Neste sentido, Rothbard (2013, p. 300) cita exemplos de como propriedade governamental e até mesmo socialismo provaram não ter soluções para o problema da poluição. Além disso, problemas com a intervenção governamental podem ser ainda mais nocivos do que aqueles que se pretende corrigir no mercado (BUTLER, 2015, p. 40).

No que tange as externalidades, Coase refletiu que estas constituíam diferenças relativas aos usos correntes e incompatíveis de um recurso que se torna escasso e dependerá da utilização mais valorizada, pois a parte que mais valoriza o direito e não o possui irá adquirir e indenizar a outra parte, garantido para si certo lucro. Mas, para que isso ocorra, é necessário que os custos de transação sejam baixos e os direitos os direitos de propriedade estejam bem definidos (COASE apud MACKAAY et al., 2015, p. 208). Logo, caso os direitos de propriedade estejam bem definidos e os custos de se chegar a um acordo entre as partes (custos de transação) são baixos, o mercado poderia resolver este problema de externalidade pela negociação (GARCIA et al., 2019, p. 27), ou seja, o mercado não aloca os recursos de forma eficiente porque os direitos de propriedade não estão perfeitamente estabelecidos. Isso significa que, se todos os recursos disponíveis em quantidade limitada tiverem um proprietário, é possível impedir que terceiros utilizem os recursos e permitir que estes recursos sejam transferíveis (MOCHÓN, 2008, p. 124).

\section{Direitos de propriedade privada bem definidos como solução de mercado para externalidades}

Várias são as teorias que tentam explicar a propriedade e suas formas de aquisição e, para este estudo, não será feita a discussão das várias correntes, adotando-se de imediato a visão de direitos naturais apenas para elucidar o tema e verificar como a propriedade privada bem definida (independentemente da discussão sobre sua justa aquisição ou distribuição) pode solucionar os problemas de externalidade. 
Nesta linha, a propriedade decorre de direitos naturais que se apoiam na constatação de que vivemos num mundo no qual as entidades tem propriedades distintas e específicas, ou seja, uma natureza distinta e que pode ser investigada pela razão do homem, por suas percepções sensoriais e por suas faculdades mentais (ROTHBARD, 2013, p. 41). Assim, os direitos naturais podem ser divididos em partes começando com direito a autopropriedade, ou seja, $\mathrm{o}$ direito absoluto de cada homem de ter a propriedade do seu próprio corpo e de controlar este corpo livre de qualquer interferência coercitiva. A propriedade de seu corpo e do exercício das faculdades para controlar esse corpo acaba fazendo o indivíduo agir para sobreviver e se sustentar e transformando os recursos dados pela natureza em bens de consumo. Deste modo, a auto propriedade do homem e de suas faculdades (liberdade) ao agir sobre a natureza com seu trabalho, lhe dá o direito de se apropriar também do resultado deste trabalho e esta é a sua propriedade (ROTHBARD, 2013, p. 46).

Esta análise vai ao encontro do argumento de John Locke em seu Segundo Tratado sobre o Governo de que cada um guarda propriedade de sua própria pessoa e sobre essa ninguém tem direito exceto ela mesma e, por meio do seu trabalho do seu corpo, misturado a um objeto tirado do estado em que a natureza o deixou, produz uma obra tornando-a sua propriedade e excluindo o direito comum dos outros homens sobre ela (LOCKE, 2005, p. 409). E este raciocínio tem como corolário que o direito de propriedade implica o direito de firmar contrato referente a esta propriedade: de doá-la ou de trocar título de propriedade pela propriedade de outra pessoa. Assim o direito do contrato deriva do direito à propriedade privada (ROTHBARD, 2010, p. 19).

\subsection{Externalidade entre agentes privados: o caso da Poluição}

Uma externalidade típica, na literatura mainstream da economia, consiste em analisar as consequências das relações de mercado entre particulares que culminam na poluição e afetam aqueles que não participaram destas relações. Essa externalidade negativa é observada com frequência no caso da poluição do ar e águas. As externalidades negativas impõem uma parcela de custo de uma atividade à terceiros (MACKAAY et al., 2015, p. 123) e fazem os mercados produzir uma quantidade maior que a socialmente desejável (MOCHÓN, 2008, p. 121).

Para muitos autores da Escola Austríaca, que defendem o direito de propriedade privada e a liberdade de mercado em níveis muito acima de outras escolas de economia, a poluição do ar pode ser resolvida com o instituto da propriedade privada, tal como já ocorre em alguns lugares com as frequências de rádio e TV ou rotas aéreas de linhas comerciais em um mercado desregulado. Neste caso, não teríamos a propriedade privada do ar propriamente dito, mas a autopropriedade, ou seja, a propriedade do próprio corpo e o direito de não ser agredido pela poluição alheia. $\mathrm{O}$ indivíduo poluidor agride a propriedade privada das vítimas, pois prejudica as pessoas (ROTHBARD, 2013, p. 302). Outro exemplo seria uma plantação privada que está sendo prejudicada por algum agente poluidor, dando ao seu dono o direito de fazer cessarem as agressões e exigir indenização pelos danos sofridos. É claro que, para a prova da relação de causa e efeito nas relações na qual estas não são óbvias, é preciso a rastreabilidade inversa da poluição sofrida pela propriedade privada até se chegar ao agente poluidor. Porém, 
conforme este instituto começa a ser aplicado e cada vez mais valorizado pelos indivíduos de uma sociedade, mais se aperfeiçoariam as técnicas para esta rastreabilidade.

No caso dos rios, na maioria das vezes, a propriedade é do governo. Rothbard (2013, p. 300) argumenta que os funcionários do governo, embora tenham o poder de controlar o recurso, não podem obter o valor de capital no mercado e assim eles não têm incentivos econômicos para conservar o valor dos rios. Como consequência, os rios acabam corrompidos e poluídos. Caso a propriedade fosse privada, o dono veria o seu patrimônio sofrer um dano e rapidamente iria cessá-lo e processar o agressor para obter a compensação pelo dano e evitar agressão futura.

Pode-se perceber que, nesses casos, uma certa quantidade de agentes privados com direitos de propriedade bem definidos pode tornar o custo da poluição demasiadamente cara para que o poluidor continue neste processo, além do fato de um maior controle e vigilância sobre os poluidores, pois o proprietário de um recurso privado, deseja evitar danos a sua propriedade (seja sua vida, saúde e corpo ou aos seus bens materiais).

\subsection{Externalidade dos Recursos Comuns e a Tragédia dos Comuns}

Os recursos comuns são aqueles cujos serviços são utilizados tanto na produção como no consumo e que não é propriedade de nenhum indivíduo particular. Dos recursos comuns surgem a externalidade negativa denominada tragédia dos bens comuns na qual os recursos comuns são utilizados em uma intensidade maior do que a desejável sobre o ponto de vista da sociedade (MOCHÓN, 2008, p. 128), ou seja, esses bens comuns tendem a ter um consumo predatório e por isso ineficiente socialmente (VASCONCELLOS et al., 2011, p. 284).

Rothbard (2013, p. 292) ilustra a resolução deste problema, por meio da propriedade privada, com o exemplo de uma mina de cobre: tendo a propriedade privada de uma mina, um indivíduo teria basicamente duas opções: ou poderia simplesmente exaurir todo seu potencial em um determinado momento (inclusive resultando em uma baixa dos preços de mercado caso a mina tenha uma produção relevante no mercado) e não ganhar mais nada no longo prazo ou tentar administrar com parcimônia, maximizando seu valor no longo prazo. Destas alternativas, pode-se esperar, visto ser mais racional e lógico para o indivíduo, a maximização do valor da mina pela exploração do metal com diligência por um longo prazo.

Caso exista uma expectativa de que o cobre venha a ser substituído no futuro por um novo metal sintético, o proprietário faria com que suas minas começassem a produzir muito mais no presente, beneficiando a economia que atualmente têm maior necessidade desse tipo de metal. Por outro lado, se no futuro projeta-se uma escassez do metal, o proprietário irá produzir menos no presente e guardar para produzir mais no futuro quando os preços estarão mais altos beneficiando assim a sociedade justamente no momento em que o produto será mais necessário. Além disso, ao deixar de produzir agora, causará uma alta no preço, que serve como um sinal para que se desenvolvam novas tecnologias e utilizações para substituílo, o que acaba aumentando ainda mais a sua conservação (ROTHBARD, 2013, p. 292).

Block (2010), em um outro exemplo sobre mineração, argumenta que embora uma pessoa possa fazer o que desejar com o terreno que possuir, os danos causados a propriedade de outras 
pessoas têm que ser por ele indenizados e que a deficiência na aplicação de leis de violação da propriedade é a causa do vínculo percebido entre esta mineração e a poluição.

Outro caso que ajuda a entender como a intervenção do governo para resolver o problema da "tragédia dos comuns" é menos eficiente do que a privatização do recurso é apresentado por Gianturco (2020) quando expõe o caso dos rinocerontes brancos que estavam sendo mortos para a coleta de seus chifres e estavam em perigo de extinção. O governo respondeu a esta situação sancionando esta prática, o que acabou criando um mercado informal no qual o preço e as margens de lucro aumentaram e as mortes continuaram. Porém, quando foi permitida a posse de rinocerontes e que estes fossem explorados economicamente, os proprietários não tinham iguais incentivos para matá-los (como os caçadores tinham) e sim de preservados para exploração longo prazo. Com essa nova medida de propriedade, a população de rinocerontes voltou aumentar.

Independente da discussão sobre a forma mais justa de se transformar os recursos comuns em propriedade privada, o fato é que, sendo recursos comuns (sobretudo os mais escassos) alocados como propriedades privadas e estas sendo garantidas com direitos de propriedade bem definidos, se evitaria o problema do consumo predatório destes recursos (tragédia dos comuns).

\subsection{Externalidade dos Bens Públicos e o Efeito Carona}

Os bens públicos são mercadorias ou serviços dos quais não se pode excluir ninguém do seu uso. Neste contexto aparece a figura do consumidor carona, isto é, aquele que goza os benefícios de um bem, mas evita pagar por isso (MOCHÓN, 2008, p. 128), sendo que uma definição precisa de direitos de propriedade restringindo o acesso a esses bens poderia ser uma solução viável para este tipo de externalidade (VASCONCELLOS et al., 2011, p. 284).

Um dos problemas que surgem com os bens públicos refere-se a questão de quais bens deveriam ser ofertados e em quais quantidades. O problema da escolha pública sobre estes aspectos envolve definição de regras de agregação de preferências individuais que também são falhas, porque a utilização de função de bem-estar social exige algum tipo de comparação das utilidades diferentes entre agentes diferentes (VASCONCELLOS et al., 2011, p. 287-288).

Esta situação pode ser resolvida pela retirada da característica de não-exclusividade do bem público, como no exemplo de transformação de uma rua em um condomínio fechado (VASCONCELLOS et al., 2011, p. 284). Isso porque, estes bens que não podem ser excluídos do consumo (não excludentes) e não despertam interesse do mercado (MOCHÓN, 2008, p. 126), quando transformados em exclusivos, sejam rivais ou não, podem ser providos privadamente (VASCONCELLOS et al., 2011, p. 284), retirando os incentivos para que cada um seja tentado a abusar do seu uso (MACKAAY et al., 2015, p. 123), isso porque, "quando os direitos de propriedade são bem estabelecidos o carona não acontece ou não é um problema relevante" (GIANTURCO, 2020).

Retirar a não-exclusividade do bem é um assunto polêmico e envolve uma definição precisa dos direitos de propriedade privada. Porém, Butler $(2015$, p. 37) alerta para como o governo acaba forçando a resolução do problema de modo coercitivo e de maneira ineficiente, 
sendo que a solução deveria envolver a possibilidade de controle e exclusão daqueles que não cooperassem com os custos.

No caso da segurança, o sistema de produtores privados de segurança que permitem a liberdade de escolha seria muito melhor do que temos atualmente - o de produção de segurança monopolista estatal (HOPPE, 2013, p. 205). Nesse sistema, apenas os proprietários que contratassem o serviço seriam protegidos no caso de agressão, restando aos demais a autodefesa ou nas situações em que o proprietário pagante não se importa que a segurança seja estendida aos proprietários não pagantes, seja por motivos de segurança geral do local (a própria empresa contratada poderia realizar a segurança adicional de não pagantes), caridade, redução de valor de seguro pelo fato da região ser mais segura etc.). A opção de poder comprar segurança de quem quiser por meio da concorrência entre produtores, faz com que a justiça seja mais barata, mais rápida, mais completa e melhor. Do contrário, teremos arbitrariedade e mau gerenciamento, com a justiça lenta e custosa, a polícia incômoda e a liberdade individual não mais respeitada (MOLINARI, 2014, p. 47-48).

Apesar da ideia de retirar a não-exclusividade do bem ser um assunto polêmico em virtude da exclusão do serviço daqueles que não pagam por ele, a solução pública para estes casos também é bastante controversa, pois antecipando o efeito carona, obriga mediante coerção a que todos paguem pelo serviço, mesmo que estes não venha a utilizá-lo, além do fato da máquina pública ser, na maioria das vezes (conforme concordam os autores da Escolha Pública e da Escola Austríaca) mais ineficiente na execução destes serviços.

Importante reforçar que, conforme expões Soto (2010), a teoria dos bens públicos foi construída nos termos estáticos do paradigma do equilíbrio, mas que escola austríaca entende o mercado como dinâmico e a função empresarial, tende a descobrir e eliminar a aparente situação de bem público por meio da criatividade empresarial nos âmbitos jurídicos e/ou tecnológica.

\section{Considerações Finais}

O processo de mercado é melhor alocador de recursos escassos da sociedade em comparação com um planejamento centralizado feito por governos e estados, e a necessidade de um agente centralizado como o estado nos casos em que supostamente o mercado falha como um agente alocador de recursos (conforme defendido pela economia mainstream), não se sustenta pelos seguintes motivos: 1) as falhas de governo são mais amplas e mais graves que as supostas falhas de mercado; 2) as supostas falhas de mercado, na grande maioria dos casos, não são criadas pelo processo de mercado, mas por uma interferência neste processo pelo estado e 3) as supostas falhas, mesmo quando criadas pelos processos de mercados, não podem ser tratadas de fato como falhas quando consideradas em um mercado livre de direitos de propriedade privada bem definidos e respeitados, pois são resolvidos no próprio processo de mercado.

Estes pontos foram analisados por meio das principais categorias de externalidades citadas pelos autores mainstream que tratam do tema e foi demonstrado como a propriedade 
privada e o livre mercado poderiam resolver (até mesmo não criar) a externalidade citada com alguns exemplos de autores da Escola Austríaca. Deste modo, analisaram-se as externalidades entre agentes particulares, as externalidades dos recursos comuns e a tragédia dos comuns e as externalidades dos bens públicos e o efeito carona.

Tem-se como limitação deste trabalho, a análise de apenas uma das supostas falha de mercado (as externalidades) que são comumente citadas na literatura mainstream, além do fato de manter a análise do ponto de vista econômico, sem entrar na discussão ética sobre intervenção do estado na propriedade privada. Assim, como sugestão para novos estudos, recomenda-se a ampliação dos estudos da solução privada por meio dos direitos de propriedade para as demais falhas de mercado.

\section{Referências}

BLOCK, Walter A. Defendendo o Indefensável. São Paulo: Instituto Ludwig Von Mises Brasil, 2010.

BUTLER, Eamonn. Escolha pública: um guia. São Paulo: Bunker Editorial, 2015.

CORDATO, Roy. The austrian theory of efficiency and the role of government. The Journal of Libertarian Studies, v. 4, n. 4, p. 393-403, 1980.

CORDATO, Roy. Toward an Austrian theory of environmental economics. The Quarterly Journal of Austrian Economics, v. 7, n. 1, p. 3-16. 2004.

CORDATO, Roy. Efficiency and Externalities in an Open-Ended Universe: A Modern Austrian Perspective. Auburn: The Ludwig von Mises Institute, 2007.

CORDEIRO, A. M. et al. Revisão Sistemática: uma revisão narrativa. Rev. Col. Bras. Cir., v. 34, n. 6, p. 428-431, 2007.

GIANTURCO, Adriano. A ciência política: uma introdução. Rio de Janeiro: Forense Universitária, 2020.

HOPPE, Hans-Hermann. Uma Teoria do Socialismo e do Capitalismo. São Paulo: Instituto Ludwig von Mises Brasil, 2013.

IORIO, Ubiratan Jorge. A Grande Ficção das Falhas de Mercado. MISES: Revista Interdisciplinar de Filosofia, Direito e Economia, São Paulo, v. 1, n. 2, p. 401-424, 2013. Disponível em: https://revistamises.org.br/misesjournal/ article/view/493/217. Acesso em: 29 set 2021.

KIRZNER, Israel. Market Theory and the Price System. Princeton: D. Van Nostrand Co., 1963.

LOCKE, John. Segundo Tratado sobre o Governo. São Paulo: Martin Claret, 2005.

MACKAAY, Ejan; ROUSSEAU, Stéphane. Análise Econômica do Direito. São Paulo: Atlas, 2015.

MAZZONI, João Fernando Rossi. Falhas de mercado no setor aeroportuário e contraposição da visão neoclássica com a escola austríaca e a escola de public choice. MISES: Revista Interdisciplinar de Filosofia, Direito e Economia, São Paulo, v. 7, n. 2, 2019. Disponível em: https://revistamises.org.br/misesjournal/article/view/1189/644. Acesso em: 29 set 2021.

MISES, Ludwig Von. Ação Humana. São Paulo: Instituto Ludwig Von Mises, 2010.

MOCHÓN, Francisco M. Princípios de economia. São Paulo: Pearson, 2008. 
MOLINARI, Gustave de. Da Produção de Segurança. São Paulo: Instituto Ludwig von Mises Brasil, 2014.

ROTHBARD, Murray. A Ética da Liberdade. São Paulo: Instituto Ludwig Von Mises Brasil, 2010.

ROTHBARD, Murray. Por Uma Nova Liberdade: O Manifesto Libertário. São Paulo: Instituto Ludwig Von Mises Brasil, 2013.

SMITH, Adam. A Riqueza das Nações: Uma Investigação sobre a Natureza e as Causas da Riqueza das Nações. São Paulo: Madras, 2018.

SOTO, Jesus Huerta de. Moeda, Crédito Bancário e Ciclos Econômicos. São Paulo: Instituto Ludwig von Mises Brasil, 2012.

SOTO, Jesús Huerta de. A Escola Austríaca: mercado e criatividade empresarial. São Paulo: Instituto Ludwig Von Mises Brasil, 2010.

VARIAN, H.R. Microeconomia: uma abordagem moderna. Rio de Janeiro: Elsevier, 2012.

VASCONCELLOS, Marco A.; PINHO, Diva B.; TONETO JR., Rudinei. Manual de Economia da USP. São Paulo: Saraiva, 2011.

VASCONCELLOS, Marco A.; GARCIA, Manuel E. Fundamentos de economia. São Paulo: Saraiva, 2019.

RECEBIDO: 11 DE AGOSTO DE 2021.

APROVADO: 17 DE OUTUBRO DE 2021. 